\title{
CLINICAL CHARACTERISTICS OF PREMENSTRUAL SYNDROME/ PREMENSTRUAL DYSPHORIC DISORDER CO-MORBID WITH PANIC DISORDER AND THE EFFECTIVENESS OF SELECTIVE SEROTONIN REUPTAKE INHIBITORS IN ITS TREATMENT
}

\author{
Rossitza K. Iakimova, \\ Daniil C. Aptalidis', \\ Milena S. Pandova ${ }^{1}$, \\ Maria B. Stoyanova, \\ Maya Y. Stoimenova-Popova ${ }^{2}$ \\ Department of Psychiatry and Medical \\ Psychology, \\ Medical University - Sofia, \\ Bulgaria \\ ${ }^{1}$ St. Naum University Hospital, \\ Sofia, \\ Bulgaria \\ ${ }^{2}$ Department of Psychiatry and \\ Medical Psychology, \\ Medical University - Pleven, \\ Bulgaria
}

\section{Summary}

Premenstrual syndrome (PMS) is often co-morbid with panic disorder (PD). Selective serotonin reuptake inhibitors (SSRIs) are the first-line treatment for both PMS and PD when they manifest separately, but their co-occurrence often complicates the treatment. Our objectives were to evaluate the clinical picture of PMS, co-morbid with PD and the way it changes under 6-month SSRI treatment course. For that purpose, we conducted a longitudinal interventional study. We examined 30 women suffering from PMS and a current episode of PD, verified through premenstrual screening tool (PSST) and Mini International Neuropsychiatric Interview (M.I.N.I.6.0.), respectively. Before treatment initiation, irritability, mood lability, anxiety, breast tension and tenderness, changes in appetite, headaches, palpitations, and abdominal bloating were most common. The somatic symptoms were more than twice as common as the psychological. After 6 months of treatment, most of the symptoms mentioned above were still present but less severe. Forty per cent of the women recovered completely. It seems that in cases of comorbidity between PMS and PD, though somatic symptoms are more common, SSRIs are an effective option for managing both somatic and psychological symptoms.

Key words: panic disorder, PMS, PMDD, SSRI, comorbidity

\section{Introduction}

Studies that examine the parallel manifestation of premenstrual syndrome (PMS)/premenstrual dysphoric disorder (PMDD) and panic disorder (PD) have found a high prevalence of PMS among patients suffering from PD. Most researchers evaluate PMS/ PMDD retrospectively and use structured interviews for assessment of PD. According to their results, between $1 \%$ and $9 \%$ of women with PMS/PMDD fulfill the criteria for PD [1-3]. Prospective studies have document an even higher rate (16-25\%) of concomitant expression of PMS and PD [4, 5]. Premenstrual exacerbation of PD has been systematically examined. A few investigations report that women with PD complain more frequently of premenstrual worsening of its symptoms, but these results were not replicated by 
prospective evaluation [6-8]. Also, yet another study finds not only a rise in the frequency of panic attacks but also mood changes during the premenstrual period [9]. Well-proved is also a vital link between PMDD and PD [10-13]. It has been shown that most women with PMDD (50$60 \%$ ) react with a heightened level of anxiety and panic attacks after being exposed to a provoking agent (lactate [14], carbon dioxide [15], cholecystokinin tetrapeptide [11], flumazenil [12]). Additionally, women with PMS/PMDD are inclined to catastrophic interpretations of physical sensations and a propensity towards anxiety, characteristic of both disorders [10].

Based on this data, the hypothesis arises that PMS consists of different subgroups, one of which is especially susceptible to PD and probably characterized by specific clinical features.

This provoked our interest to clarify the clinical picture of PMS co-morbid with PD and the influence on its symptoms of six-month treatment with selective serotonin reuptake inhibitors (SSRIs).

\section{Materials and Methods}

\section{Subject selection}

We enrolled 30 women suffering from PMS and PD simultaneously. We evaluated the clinical characteristics, the symptoms' severity, the ratio of somatic to psychological symptoms, and the symptom change during SSRIs treatment. The sample was gathered in out- as well as inpatient conditions among women searching treatment for a first or recurrent episode of PD who were eligible to SSRI treatment for that reason. Diagnoses were based on the International classification of diseases 10th edition (ICD 10) using the Mini International Neuropsychiatric Interview (M.I.N.I.6.0.), as well as a standardized screening questionnaire for retrospective evaluation of premenstrual symptoms in the preceding 12 months.

\section{Inclusion criteria}

fertile age (18 to 50 years), regular menstrual cycle of 21 to 35 days duration.

\section{Exclusion criteria}

current or in the preceding 3 months lactation, any gynaecological condition or use of hormonal medications with a possible influence on the physiological cyclicality of female sex hormones.

The eligible patients were offered to participate in the study. Their condition was followed up twice (at third and sixth month) using the same questionnaire.

All participants signed written informed consent before initiating the study procedures. The study design was granted permission by the Ethics Committee Medical Center "St. Naum".

\section{Diagnostic instruments}

M.I.N.I.6.0. is a brief psychiatric interview that was developed to aid diagnosing Diagnostic and Statistical Manual of Mental Disorders, 4th edition (DSM-IV) and ICD 10 disorders. It has been validated against the structured clinical interview for DSM (SCID), Composite International Diagnostic Interview for ICD 10 (CIDI) and professional opinion of the expert panel [16].

Premenstrual symptoms screening tool (PSST) The questionnaire we used to evaluate the presence and severity of PMS/PMDD was developed based on the PSST [17]. With the purpose of precise evaluation of somatic symptoms, we examined them separately. The symptoms identified by the patient should have been present for two weeks before menses during the previous twelve months (two months for the follow-up visits) - the affirmative answers to whichever question needed further evaluation as mild, moderate, or severe. The severity of PMS was defined based on this rating. Severe PMS corresponds to PMDD.

The verification of $\mathrm{PD}$, its severity, the selection of SSRI as an antidepressant class and the specific medication as a treatment option were determined by a trained psychiatrist.

\section{Statistical analysis}

For data analyses, we used SPSS version 13.0. Besides descriptive and frequencies statistics, we run Kolmogorov-Smirnov and Shapiro-Wilk tests for testing the normality of distribution, followed by Wilcoxon Signed Ranks Test for comparing two related groups in case of nonnormal distribution and McNemar's test for testing the change in variables dynamically. We assumed statistical significance at $\mathrm{p}<0.05$. 


\section{Results}

We recruited 35 women altogether. Five of them dropped out because of inaccurate completion of the questionnaire, non-compliance and premature termination of medication intake, failure to show up at a follow-up visit. We analyzed and presented the data gathered from 30 women. The participants were aged between

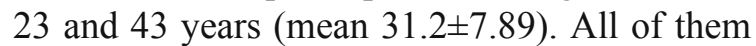
were started on SSRIs: citalopram - 12 women; fluoxetine -4 women; paroxetine -15 women; escitalopram - 9 women.

Before treatment, the most common psychological symptoms were irritability and changes in appetite $(100.0 \%)$, followed by mood swings, anxiety, and fatigue $(90.0 \%)$, changes in sleep pattern $(86.7 \%)$, depressed mood $(80 \%)$, apathy (76.7\%), and lack of concentration (83.3\%). Despondency, sweets craving were also equally distributed $-73.3 \%$. The most common severe symptoms were irritability (86.7\%), anxiety $(73.3 \%)$, and sweets craving $(40 \%)$. Severe apathy was observed in none of the participants.

Among somatic symptoms, the most prevalent were tension, breast tenderness, weight gain, headaches, and palpitations (100\%). Many of the subjects also suffered from muscle aches (93.3\%), abdominal bloating (90\%), shivering (86.7\%), and joint aches (63.3\%). Most commonly severely expressed were breast swelling and tenderness (70\%), palpitations (60\%), abdominal bloating (50\%), and shivering (43.3\%).

Most of the women experienced moderately severe PMS (56.7\%) and the rest of them (43.3\%) - severe PMS (Figure 1).

The clinical picture of PMS co-morbid with PD was dominated by somatic symptoms, which

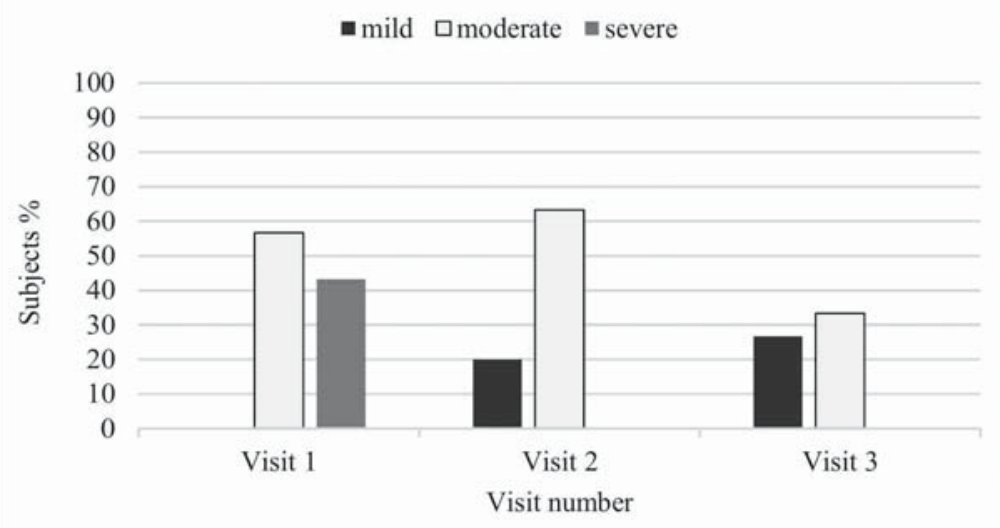

Figure 1. Severity of PMS with comorbid PD (\%)

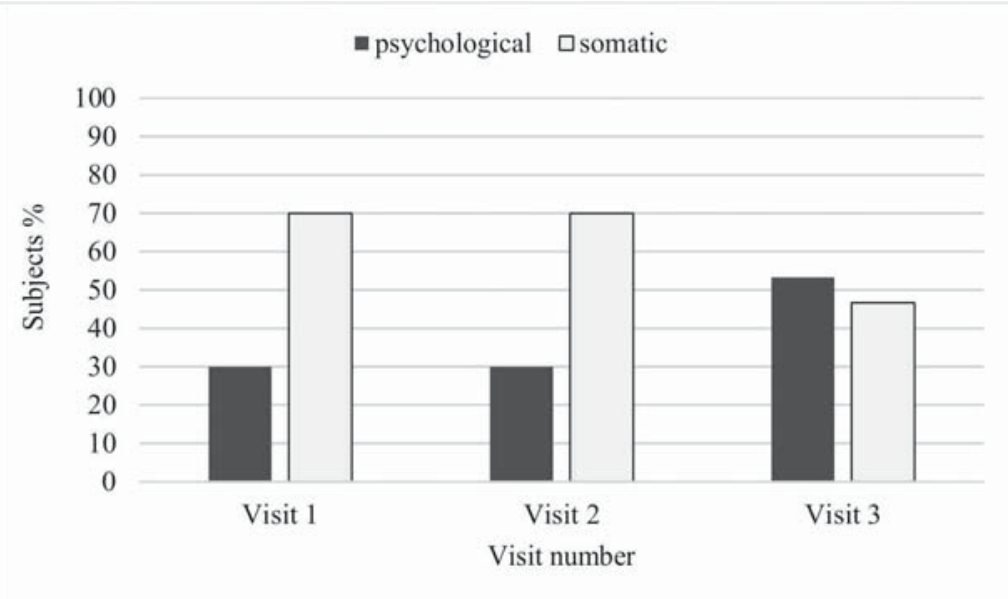

Figure 2. Prevalence of symptoms by type (\%) 
were more than twice (2.33) more prevalent than psychological (Figure 2).

Three months after initiation of SSRIs intake, the prevalence of the psychological symptoms remained unchanged. All patients experienced anxiety (100\%), which in $20 \%$ of them was severely expressed. Commonly present were also mood swings, irritability, appetite changes $(83.3 \%)$, sweets craving (73.3\%), lack of concentration (73.2\%), and fatigue (60\%). Among the most prevalent somatic symptoms were breast tension and tenderness (96.7\%), which was severe in $40 \%$ of the women, headaches and abdominal bloating (90\%), palpitations $(86.7 \%)$, muscle aches $(73.3 \%)$, shivering, weight gain $(66.7 \%)$.

Psychological to somatic symptoms ratio remained approximately the same compared to visit 1 (0.43) - Figure 2.

At visit 3 (after 6 months of medication intake) most common of the psychological symptoms were irritability and anxiety (90\%) (severe in $20 \%$ and $10 \%$ of them, respectively), mood swings $(86.7 \%)$, changes in appetite $(76.7 \%)$, sweets cravings $(73.3 \%)$, lack of concentration $(60 \%)$. Concerning somatic symptoms, nearly all participants still complained of breast tension and tenderness $(83.3 \%)$, palpitations $(73.3 \%)$, abdominal bloating (70\%), shivering (56.7\%).

The ratio of psychological to somatic symptoms was 1.14 (Figure 2).

Three months after initiation of treatment with SSRIs, all psychological symptoms except for mood swings $(p=0.227)$ were significantly ameliorated (Table 1). Somatic symptoms were slightly improved. Breast tension and

Table 1. Comparisons of symptoms' prevalence, severity of PMS, and psychological to somatic symptoms ratio between visits

\begin{tabular}{|c|c|c|c|c|c|c|}
\hline \multirow{2}{*}{ Psychological symptoms } & \multicolumn{2}{|c|}{ Visit $1 / 2^{*}$} & \multicolumn{2}{|c|}{ Visit $1 / 3^{*}$} & \multicolumn{2}{|c|}{ Visit 2/3* } \\
\hline & $\mathrm{Z}$ & $\mathrm{p}$ & $\mathrm{Z}$ & $\mathrm{p}$ & $\mathrm{Z}$ & $\mathrm{p}$ \\
\hline Depressed mood & -4.179 & $<0.001$ & -4.378 & $<0.001$ & -4.258 & $<0.001$ \\
\hline Irritability & -4.187 & $<0.001$ & -4.363 & $<0.001$ & 0.000 & 1.000 \\
\hline Mood swings & -1.208 & 0.227 & -3.316 & 0.001 & -3.626 & $<0.001$ \\
\hline Anxiety & -2.150 & 0.032 & -4.443 & $<0.001$ & -3.578 & $<0.001$ \\
\hline Hopelessness & -4.456 & $<0.001$ & -4.208 & $<0.001$ & -1.000 & 0.317 \\
\hline Apathy & -3.285 & 0.001 & -3.520 & $<0.001$ & -0.577 & 0.564 \\
\hline Poor concentration & -4.128 & $<0.001$ & -4.123 & $<0.001$ & -2.333 & 0.020 \\
\hline Fatigue & -4.211 & $<0.001$ & -4.348 & $<0.001$ & -2.500 & 0.012 \\
\hline Changes in appetite & -4.244 & $<0.001$ & -4.018 & $<0.001$ & -0.184 & 0.854 \\
\hline Sweets craving & -3.106 & 0.002 & -2.273 & 0.023 & 0.000 & 1.000 \\
\hline Sleep changes & -4.311 & $<0.001$ & -4.457 & $<0.001$ & -2.449 & 0.014 \\
\hline \multirow{2}{*}{ Somatic symptoms } & \multicolumn{2}{|c|}{ Visit $1 / 2 *$} & \multicolumn{2}{|c|}{ Visit $1 / 3^{*}$} & \multicolumn{2}{|c|}{ Visit $2 / 3^{*}$} \\
\hline & $\mathrm{Z}$ & $\mathrm{p}$ & $\mathrm{Z}$ & $\mathrm{p}$ & $\mathrm{Z}$ & $\mathrm{p}$ \\
\hline Abdominal bloating & -3.704 & $<0.001$ & -4.008 & $<0.001$ & -3.276 & 0.001 \\
\hline Weight gain & -3.682 & $<0.001$ & -4.244 & $<0.001$ & -1.414 & 0.157 \\
\hline Breast tension and tenderness & -2.754 & 0.006 & -3.402 & 0.001 & -2.460 & 0.014 \\
\hline Joint pain & -4.001 & $<0.001$ & -3.852 & $<0.001$ & -2.000 & 0.046 \\
\hline Muscle pain & -4.354 & $<0.001$ & -4.294 & $<0.001$ & -3.317 & 0.001 \\
\hline Headaches & -3.626 & $<0.001$ & -4.038 & $<0.001$ & -2.434 & 0.015 \\
\hline Palpitations & -4.326 & $<0.001$ & -4.850 & $<0.001$ & -3.071 & 0.002 \\
\hline Shivering, hot and cold flashes & -4.058 & $<0.001$ & -4.476 & $<0.001$ & -2.652 & 0.008 \\
\hline PMS severity & -4.457 & $<0.001$ & -4.484 & $<0.001$ & -2.909 & 0.004 \\
\hline $\begin{array}{l}\text { Psychological to somatic } \\
\text { symptoms }\end{array}$ & $1.000 \dagger$ & & $0.016 \dagger$ & & $0.016 \dagger$ & \\
\hline
\end{tabular}

*Wilcoxon Signed Ranks Test; †McNemar test 
tenderness remained the leading symptom, but its severity also decreased - from $70 \%$ to $40 \%$ of the participants. Generally, the prevalence of somatic symptoms was significantly reduced $(\mathrm{p}<0.05)$, but they still dominated the clinical picture. No statistically significant difference was observed in the ratio of somatic to psychological symptoms $(\mathrm{p}=0.027)$. The severity of the syndrome itself was also ameliorated - the cases of severe PMS decreased in number and in $16.7 \%$ of the participants were fully resolved.

After six months of treatment, all psychological symptoms were reduced in frequency and severity. Mood swings, anxiety, lack of concentration, fatigue, sleep changes were statistically significantly improved, compared to visit $2(\mathrm{p}<0.05)$ - Table 1 . At visit 3 , all somatic symptoms except weight gain were statistically significantly improved (Table 1). The prevalence of psychological and somatic symptoms became nearly equal.

In $40 \%$ of the participants, full resolution of PMS symptoms was accomplished and in another one-fourth of them only mild or moderate symptoms persisted. Compared to visit 2, we found a statistically significant difference in respect to the syndrome severity $(p=0.004)$, which means that the improvement with treatment was retained.

\section{Discussion}

The presented study was an attempt to clarify the clinical picture of PMS co-morbid with PD and to follow its response to the initiation of treatment with SSRIs. According to our results, the co-morbidity was related to the dominance of somatic symptoms. Moreover, the presence of PD was associated with the appearance of physical symptoms specific to the premenstrual period. In the available literature, there is a lack of information on the typical presentation of PMS in cases of comorbidity with PD, so any kind of comparison to our results is not feasible until replication studies appear.

In our sample, $56.7 \%$ of the women suffered from moderately severe PMS and $43.3 \%$ from PMDD. We observed no cases of the mildly expressed syndrome, even though such cases were not intentionally excluded from the study. The summarized data from previous investigations on the distribution of PMDD points to a prevalence of around 8\% [18-21], but it has not been evaluated in the presence of comorbidity with PD. In our opinion, the probable reason why our results on the prevalence of PMDD were so high is that our study sample consisted of women suffering from both disorders simultaneously.

In our sample, despite the comorbidity and greater severity of PMS (43.3\% of the participants suffered PMDD), all psychological symptoms improved statistically significantly $(p<0.001)$ during the 6 months of treatment. Similar results were reported by Halbreich et al. (2006) [22]. They analyzed the data from clinical studies on SSRIs regarding their efficacy on particular symptoms of PMS and found that SSRIs reliably improved the psychological symptoms anger, irritability, mood swings, tension, and depression in patients without psychiatric comorbidity. Our results corroborate their findings and additionally demonstrate that SSRIs effectively ameliorate the severe psychological symptoms in cases of PMS co-morbid with PD. Regarding somatic symptoms at the end of the 6-month treatment period, the prevalence of all of them reduced significantly $(\mathrm{p}<0.001)$. Least improved were breast tension and tenderness. The ratio of psychological to somatic symptoms gradually equalized, and at visit 3 , it was 1.14 . The prevalence of somatic symptoms decreased from $70 \%$ at visit 1 to $46.7 \%$ at visit 3 , which highlights the effectiveness of SSRIs on somatic symptoms.

This data is comparable to what is known from some of a large number of randomised placebo-controlled studies on the effectiveness of SSRIs in the treatment of PMS. All of them emphasize the improvement in psychological symptoms (especially irritability) but also in somatic (breast tension and abdominal bloating) [23-28]. Further evidence for a direct effect of SSRIs on somatic symptoms can be found when comparing intermittent versus continuous dose regimens. It seems that continuous intake (the regimen used in the presented study) is related to a reduction in somatic symptoms and intermittent intake - only with improvement in psychological ones [22]. This way, our results give further confirmation of the effectiveness of SSRIs on somatic symptoms of PMS. However, 
unlike previous research, our sample consisted of patients suffering from both PMS and PD [22] summarized that independent of the treatment regimen, psychological symptoms were reliably improved, while the effect of SSRIs on somatic symptoms is much more variable. Our findings do not corroborate such a conclusion, but a sensible improvement was observable in more than three months of treatment.

Closer to our results is the data from a metaanalysis by Dimmock et al. (2000) [29]. They claim that SSRIs are effective for both somatic and behavioral symptoms. But not all studies included in this meta-analysis assess the somatic symptoms systematically, so the conclusions based on them should be taken with caution. To override this flaw, we modified PSST, so we were able to perform a detailed assessment of somatic symptoms and to show an improvement in them under SSRIs treatment. Once again, our results are based on a sample of PMS patients with comorbidity, so our study fills a gap in the available research in the field.

Criteria for the effectiveness of SSRIs treatment include also change in the severity of PMS. Before treatment initiation, $56.7 \%$ and $43.3 \%$ suffered moderate and severe PMS, respectively. At the end of the follow-up period, $40 \%$ of the patients were symptom-free, meaning the syndrome was resolved entirely. In $26.7 \%$ of them, there were only mild complaints, and in $33.3 \%$ - moderately severe. Cases of severe PMS were not registered.

The presented data gives us a reason to summarize that the effectiveness of SSRIs makes them a renowned first-line treatment for PMS [30-32], but our results also allow us to claim them further effective in cases of co-morbid PD.

\section{Conclusions}

The dominance of somatic symptoms characterizes the typical clinical picture of untreated PMS co-morbid with PD. A continuous regimen of SSRIs intake brings a gradual improvement in symptoms. Severe cases of PMS are resolved, and $40 \%$ of the patients are symptom-free. SSRIs are effective for psychological as well as somatic symptoms of PMS co-morbid with PD.

\section{Acknowledgements}

The authors have explicitly stated that there is no conflict of interest in connection with this article. No funding or compensation was received for authoring this manuscript.

\section{References}

1. Pearlstein TB, Frank E, Rivera-Tovar A, Thoft JS, Jacobs E, Mieczkowski TA. Prevalence of axis I and axis II disorders in women with late luteal phase dysphoric disorder. J Affect Disord. 1990;20(2):129-34.

2. Chandraiah S, Levenson JL, Collins JB. Sexual dysfunction, social maladjustment, and psychiatric disorders in women seeking treatment in a premenstrual syndrome clinic. Int J Psychiatry Med. 1991;21(2):189-204.

3. Stout AL, Steege JF, Blazer DG, George LK. Comparison of lifetime psychiatric diagnoses in Premenstrual Syndrome Clinic and community samples. J Nerv Ment Dis. 1986;174(9):517-22.

4. Harrison WM, Endicott J, Nee J, Glick H, Rabkin JG. Characteristics of women seeking treatment for premenstrual syndrome. Psychosomatics. 1989;30(4):405-11.

5. Fava M, Pedrazzi F, Guaraldi GP, Romano J, Genazzani AR, Facchinett F. Comorbid anxiety and depression among patients with late luteal phase dysphoric disorder. J Anx Disord. 1992;6(4):325-35.

6. Cameron OG, Kuttesch D, McPhee K, Curtis GC. Menstrual fluctuation in the symptoms of panic anxiety. J Affect Disord. 1988;15:169-74.

7. Cook BL, Noyes R, Garvey MJ, Beach V, Sobotka J, Chaudhry D. Anxiety and the menstrual cycle in panic disorder. J Affect Disord. 1990;19(3):221-6.

8. Stein MB, Schmidt PJ, Rubinow DR, Uhde TW. Panic disorder and the menstrual cycle: panic disorder patients, healthy control subjects, and patients with premenstrual syndrome. Am J Psychiatry. 1989;146(10):1299-303.

9. Kaspi S, Otto MW, Pollack MH, Eppinger S, Rosenbaum JF. Premenstrual exacerbation of symptoms in women with panic disorder. J Anx Disord. 1994;8(2):131-8.

10. Vickers K, McNally RJ. Is premenstrual dysphoria a variant of panic disorder? A review. Clin Psychol Rev. 2004;24(8):933-56.

11. Le Melledo JM, Bradwejn J, Koszycki D, Bichet D. Premenstrual dysphoric disorder and response to cholecystokinin-tetrapeptide. Arch Gen Psychiatry. 1995;52(7):605-6. 
12. Le Melledo J, Van Driel M, Coupland NJ, Lott P, Jhangri GS. Response to flumazenil in women with premenstrual dysphoric disorder. Am J Psychiatry. 2000;157(5):821-3.

13. Adewuya AO, Loto OM, Adewumi TA. Premenstrual dysphoric disorder amongst Nigerian university students: prevalence, comorbid conditions, and correlates. Arch Womens Ment Health. 2008;11(1):13-8.

14. Schwartz GE, Goetz RR, Klein DF, Endicott J, Gorman JM. Tidal volume of respiration and "sighing" as indicators of breathing irregularities in panic disorder patients. Anxiety. 1996;2(3):145-8.

15. Harrison WM, Sandberg D, Gorman JM, Fyer M, Nee J, Uy J, et al. Provocation of panic with carbon dioxide inhalation in patients with premenstrual dysphoria. Psychiatry Res. 1989;27(2):183-92.

16. Sheehan DV, Lecrubier Y, Sheehan KH, Amorim P, Janavs J, Weiller E, et al. The Mini International Neuropsychiatric Interview (M.I.N.I.): the development and validation of structured diagnostic psychiatric interview for DSM-IV and ICD-10. J Clin Psychiatry. 1998;59(Suppl 20):22-33.

17. Steiner M, Macdougall M, Brown E. The premenstrual symptoms screening tool (PSST) for clinicians. Arch Womens Ment Health. 2003;6(3):203-9.

18. Matsumoto TH, Asakura T, Hayashi $\mathrm{T}$. Biopsychosocial aspects of premenstrual syndrome and premenstrual dysphoric disorder. Gynecol Endocrinol. 2013;29(1):67-73.

19. Miyaoka Y, Akimoto Y, Ueda K, Ujiie Y, Kametani M, Uchiide Y, et al. Fulfillment of the premenstrual dysphoric disorder criteria confirmed using a self-rating questionnaire among Japanese women with depressive disorders. Biopsychosoc Med. 2011 2;5:5.

20. Cohen LS, Soares CN, Otto MW, Sweeney BH, Liberman RF, Harlow BL. Prevalence and predictors of premenstrual dysphoric disorder (PMDD) in older premenopausal women. The Harvard Study of Moods and Cycles. J Affect Disord. 2002;70(2):125-32.

21. Sehlo MG, Youssef UM, Mahdy RS, El-Gohari H. Prevalence and symptoms of premenstrual dysphoric disorder in a sample of psychiatric patients at Zagazig University Hospitals. Egypt J Psychiatry. 2018;39(2):83-8.

22. Halbreich U, O’Brien PM, Eriksson E, Backstrom T, Yonkers KA, Freeman EW. Are there differential symptom profiles that improve in response to different pharmacological treatments of premenstrual syndrome/ premenstrual dysphoric disorder? CNS Drugs.
2006;20(7):523-47.

23. Kim DR, Gyulai L, Freeman EW, Morrison ME, Baldassano C, Dube B. Premenstrual dysphoric disorder and psychiatric co-morbidity. Arch Womens Ment Health. 2004;7(1):37-47.

24. Breaux C, Hartlage S, Gehlert S. Relationships of premenstrual dysphoric disorder to major depression and anxiety disorders: a reexamination. J Psychosom Obstet Gynecol. 2000;21(1):17-24.

25. Yonkers KA, Halbreich U, Freeman E, Brown C, Endicott J, Frank E, et al. Symptomatic improvement of premenstrual dysphoric disorder with sertraline treatment. a randomized controlled trial. Sertraline Premenstrual Dysphoric Collaborative Study Group. JAMA. 1997;278(12):983-8.

26. Landen M, Nissbrandt H, Allgulander C, Sörvik K, Ysander C, Eriksson E. Placebo-controlled trial comparing intermittent and continuous paroxetine in premenstrual dysphoric disorder. Neuropsychopharmacology. 2007;32(1):15361.

27. Steiner M, Pearlstein T, Cohen LS, Endicott J, Kornstein SG, Roberts C, et al. Expert guidelines for the treatment of severe PMS, PMDD, and comorbidities: the role of SSRIs. J Womens Health (Larchmt). 2006;15(1):57-69.

28. Steiner M, Romano SJ, Babcock S, Dillon J, Shuler C, Berger C, et al. The efficacy of fluoxetine in improving physical symptoms associated with premenstrual dysphoric disorder. BJOG. 2001;108(5):462-8.

29. Dimmock PW, Wyatt KM, Jones PW, O’Brien PM. Efficacy of selective serotonin-reuptake inhibitors in premenstrual syndrome: asystematic review. The Lancet. 2000;356(9236):1131-6.

30. O'Brien PM, Backstrom T, Brown C, Dennerstein L, Endicott J, Epperson CN, et al. Towards a consensus on diagnostic criteria, measurement and trial design of the premenstrual disorders: the ISPMD Montreal consensus. Arch Womens Ment Health. 2011;14(1):13-21.

31. Walsh S, Ismaili E, Naheed B, O'Brien S. Diagnosis, pathophysiology and management of premenstrual syndrome. Obstet Gynaecol. 2015;17:99-104.

32. Marjoribanks J, Brown J, O’Brien PM, Wyatt K. Selective serotonin reuptake inhibitors for premenstrual syndrome. Cochrane Database Syst Rev. 2013;7(6):CD001396. 